\title{
Distinct Morpho-Physiological Responses of Maize to Salinity Stress
}

\section{Tshegofatso Bridget Dikobe*, Boitumelo Mashile, Rotondwa Rabelani Sinthumule, Oziniel Ruzvidzo}

Department of Botany, School of Biological Sciences, North-West University, Mmabatho, South Africa

Email: ${ }^{\star T}$ Tshegofatso.Dikobe@nwu.ac.za

How to cite this paper: Dikobe, T.B., Mashile, B., Sinthumule, R.R. and Ruzvidzo, O. (2021) Distinct Morpho-Physiological Responses of Maize to Salinity Stress. American Journal of Plant Sciences, 12, 946-959. https://doi.org/10.4236/ajps.2021.126064

Received: May 6, 2021

Accepted: June 26, 2021

Published: June 29, 2021

Copyright () 2021 by author(s) and Scientific Research Publishing Inc. This work is licensed under the Creative Commons Attribution International License (CC BY 4.0).

http://creativecommons.org/licenses/by/4.0/

\section{(c) (i) Open Access}

\begin{abstract}
Most plants demonstrate wide interactive and complex adaptive morphological, biochemical, and physiological responses when subjected to salinity stress. Salt stress negatively impacts agricultural yields more especially cultivated crops throughout the world. Of interest to this study is maize a saltsensitive crop that is widely grown worldwide, and receiving most attention due to its significant attributes and ability to serve as a great model for stress response studies. We exposed QN701 maize cultivar, to simulated salinity stress and investigated its morphological and physiological responses. Salinity negatively induced various morphological responses such as the reduction in plant height, number of leaves, shoot and root (length and biomass), and leaf width; however, it significantly increased the leaf area. On the physiological aspect, salt stress decreased the number of stomata, stomatal density, and photosynthesis, while it increased the respiration rate. This study expanded our knowledge of the morphological and physiological responses of maize to salinity stress. Additionally, these findings may serve as a recommendation for salinity breeding programs in maize and related cereal crops.
\end{abstract}

\section{Keywords}

Zea mays, Salt Stress, Plant Morpho-Physiological Response, Photosynthesis, Respiration

\section{Introduction}

Maize (Zea mays L.) is a well-known important cereal crop among others such as rice and wheat that is considered as the main staple food. Tons of maize hectares are grown annually in South Africa and other parts of the world indicating its economic importance. Maize is a C4 species that is moderately sensitive to sa- 
linity and has a range of genotypic variability which enables it to be widely cultivated under varying soil types and climate conditions [1]. In addition, its grains contain bioactive phytochemicals such as phenolics, carotenoids and phytosterols [2]. Maize is not only used as a food product; more importantly it is a major grain in animal feed with a potential as a bioenergy source. Among all of the major crops, the yield and performance of maize is negatively affected by osmotic stress induced by drought or salt stress [3].

Salt stress is one of the major abiotic stresses that results in a decline in plant productivity worldwide, especially in arid and semi-arid regions [4]. In the arid areas, rainfall that is too low to leach salts from the soil and high evaporation rates aggravate salts-build up in soil [5]. This condition has severe effects on plant growth which can be attributed either to an osmotic effect, specific ion effect and nutritional imbalance or induced oxidative stress [6]. These effects often manifest as plant death or deterioration on plant growth, increased respiration rates and decreased photosynthesis efficiency [7]. Decrease in photosynthesis rates results in reduced plant growth, including root growth, which leads to a reduction in yield [8].

Normally, when plants are subjected to salt stress they encounter various effects such as the lowering of water potential which leads to dehydration of tissues, specific ion effects, and nutrient imbalance, whereby high absorption of $\mathrm{Na}^{+}$and $\mathrm{Cl}^{-}$ions disturb essential mineral uptake [9]. Additional salt stress effects, include stomatal closure which avoids water loss, limits carbon dioxide $\left(\mathrm{CO}_{2}\right)$ fixation, and increases the production of reactive oxygen species (ROS) which leads to oxidative damage in the cellular components that are manifested as enzyme deactivation, protein degradation, and DNA damage [10]. Soil salinity is a complex phenotypic and physiological phenomenon in plants, that imposes ion imbalance, ionic and osmotic stress, inducing oxidative stress and negatively influencing metabolic activities in crop plants that result in a decreased productivity [11]. It has been predicted that if soil salinity stress could continue like this, it will result in the loss of about $50 \%$ of the present agricultural lands by 2050 [12]. Major plant processes such as growth, photosynthesis, lipid metabolism, and protein synthesis are affected when osmotic and water potential in tissues decreases. In addition, salt stress results in a significant decrease in plant height, root, and shoot [13]. It is also known to decrease the process of photosynthesis, by decreasing both the leaf area as well as the chlorophyll content. This is due to metabolic damage or stomatal closure [14].

In view of the rising salt stress, plants have to adapt to such stress for their survival. Hence, as an adaptation mechanism plants need to produce a number of compatible solutes, non-enzymatic and enzymatic antioxidant to protect their cells against cellular damage [15]. Although several physiological, morphological and biochemical responses have been shown to be induced by salinity stress in various crops [16] [17] [18] [19] [20]. The extent to which salinity affects crop yield strongly depends on genera, species, and cultivars within certain species [21]. 
With all of those mentioned economic importance of maize and its variability in salt tolerance among genotypes. Hence, our study was designed to investigate the effects of salt stress on the morphology and physiology in particular the photosynthesis and respiration rates during the development of a QN701 maize cultivar. Up to date, no information has been reported on the morphological and physiological responses of this cultivar under salinity stress. Thus this study would assist the scientific community with the knowledge on mechanisms used to improve salinity stress tolerance for maize and related grain crop breeding programs.

\section{Materials and Methods}

\subsection{Plant Material and Maintenance of Plant Growth Conditions}

Zea mays (QN701) cultivar seeds were obtained from Quality Seed (Dalton, KwaZulu-Natal, RSA). Four seeds per pot were selected for size homogeneity and good quality. Approximately twenty-four seeds were surface sterilized with $2 \mathrm{ml} \mathrm{70 \%} \mathrm{(v/v)} \mathrm{ethanol} \mathrm{in} 50 \mathrm{ml}$ falcon tube (4 per tube) which was vortexed for 1 minute. The supernatant was discarded, followed by further sterilization with 2 $\mathrm{ml} 1.25 \%(\mathrm{v} / \mathrm{v})$ sodium hypochlorite solution (bleach) to the seeds and vortexed for 10 minutes. Immediately after sterilization, bleach was discarded and the seeds were rinsed three times with $3 \mathrm{ml}$ of sterile distilled water. All the sterilized seeds, about four seeds were sown in each of the six, $14 \mathrm{~cm}$ plastic plant pots filled with a 3:2(v/v) mixture of sterilized potting soil (Culterra, Muldershift, South Africa) and vermiculite. The sown seeds were watered daily with $100 \mathrm{ml}$ of sterile water up until germination started on the $7^{\text {th }}$ day. The germinated seedlings were grown on a $26^{\circ} \mathrm{C} / 22^{\circ} \mathrm{C}$ day/night temperature cycle and a $16 / 8$ hours light/dark regime with a photon flux density of $300 \mu \mathrm{mol} \mathrm{m} \mathrm{m} \mathrm{s}^{-1}$ during the day (light) for a period of 16 days. Plants were allowed to grow in a randomized form to eliminate the effect of variations in environmental conditions at different positions. All plants that were of the same developmental stage (1 week after germination) and of similar height were selected for further experimental procedures and divided into two groups for the control and salt treatments.

\subsection{Salinity Stress Treatments}

The two groups of plants were subjected to treatment. Salinity stress was imposed by irrigating the experimental plants with $100 \mathrm{ml}$ of $200 \mathrm{mM} \mathrm{NaCl}(\mathrm{w} / \mathrm{v})$ solution at a two-day interval for 16 days, while the control plants were irrigated with water only under the same conditions. Both groups of plants were set up in a randomized design with three replications.

\subsection{Plant Sampling and Evaluation of Morphological Parameters}

Morphological parameters concerned plant height, leaf number per plant pot, leaf epidermal structure (stomatal count), shoot (length and weight) and root (length and weight) were determined on day 16 after treatment. Morphological 
analysis were performed on all the six harvested plants obtained from the section 2.2 by measuring the plant height $(\mathrm{cm})$, counting the number of leaves in each plant pot, measuring leaf length $(\mathrm{cm})$ and width $(\mathrm{cm})$, shoot and root length $(\mathrm{cm})$ using a ruler. Fresh root and shoot weights $(\mathrm{g})$ were measured from all the six plants (control and experiment) using Radwag weighing balance (Model: PS 750/C/2, Lasec, Midrand, South Africa). The leaf area was then calculated according to [22] formula:

$$
\text { Leaf area }=L \times W \times A
$$

where $L$ is length, $W$ is width and $A=0.75$ as a constant coefficient.

\subsection{Estimation of the Physiological Parameters}

\subsubsection{Determination of Stomatal Number and Stomatal Density}

To determine the stomatal number and density we followed nail polish imprint method as described by Voleníková and Tichá [23]. Three fully developed fresh maize leaves from each of the six pots for both the control (water only) and experimental (salt treated) plants were randomly selected and carefully detached from the shoots. Each leaf from both control and treatment upper and lower surfaces was identified followed by cutting them into small sizes that can fit on a microscope slide. On each of the leaf surfaces (upper and lower side), a thin layer of clear nail polish was spread and allowed to dry. Once the nail polish was dry, a strip of clear stick tape was placed over the pieces of the leaf (upper and lower side). Immediately after placing stick tape, the tape was pressed down to make good contact with the nail polish. The sticky tape was peeled off from each leaf surface (upper and lower), followed by placing the tape with leaf impressions side by side on a microscope slide. Impressions were examined using a high resolution Primo Star light microscope (Carl Zeiss, Cape Town, South Africa) at $400 \mathrm{x}$ magnification with the field of view of $0.05 \mathrm{~mm}$. The micrographs were imaged with a digital camera coupled to a Primo Star light microscope (Carl Zeiss, Cape Town, South Africa). The obtained micrographs were then used to determine the number of stomata. The field of view (FOV), area of FOV and stomatal density were calculated following the equations described by Voleníková and Tichá [23]:

$$
\mathrm{FOV}=\frac{\text { field number }}{\text { magnification number }}
$$

$$
\text { Area of } \mathrm{FOV}=\pi r^{2}
$$

where $\pi=3.14, r^{2}=$ radius of the field of view,

$$
\text { stomatal density }=\frac{\text { number of stomata in entire FOV }}{\operatorname{Area}\left(\mathrm{mm}^{2}\right)}
$$

\subsubsection{Measurements of Photosynthesis and Respiration Rates}

A day before sampling and harvesting, the net photosynthetic (A) and respiration rates were determined from all sets of plant groups using an LCpro-SD leaf 
chamber (ADC BioScientific, Hertfordshire, UK). For both groups of plants (control and experiments) three leaves from each plant pot were randomly selected and enclosed in the leaf chamber of the portable LCpro-SD system which was set to keep all environmental factors at ambient state. All the readings were recorded from the adaxial surface of the leaf on three independent biological replicates for each treatment group (control and experiment). The resultant readings displayed on the device's screen were taken for 3 minutes at 10-second intervals. The readings for photosynthesis rates were recorded and all the negative values of different rates of photosynthesis were recorded as values of respiration rates and used to plot the photosynthesis and respiration graphs against time.

\subsection{Data Analysis}

All the morphological and physiological data obtained from 3 biological replicates per treatment were subjected to analysis of variance (ANOVA) (SuperAnova, Statsgraphics Version 7, 1993, Statsgraphics Corporation, USA). Furthermore, post hoc Student Newman Kuehls (SNK), multiple range test $(\mathrm{p} \leq 0.05)$ was performed to separate the significant differences between treatments $(n=3)$.

\section{Results}

\subsection{Morphological and Growth Responses of Zea mays to Salt Stress}

Phenotypic parameters for the control and treated maize plants were recorded after 16 days as presented in Table 1 . The number of leaves per plant was reduced, with the control having greater number of leaves as compared to the experiment (Figure 1(a)). An increased leaf area was observed on the salinity treated (experimental) plants than the untreated (control) plants (Figure 1(b)), while there was a decline on the leaf width for the treated plants compared to the untreated plants (Figure 1(c)). A slight reduction on plant height was noticed on the salinity treated plants with about $43 \mathrm{~cm}$ compared to the control plants with $44 \mathrm{~cm}$ (Figure 2(a)). Furthermore a decrease in the shoot and root (length and fresh weight) was evident in the experimental plants (Figures 2(b)-(e)).

Table 1. Phenotypes of control and experimental QN701 maize cultivar 16 days after treatment.

\begin{tabular}{cccccccccc}
\hline $\begin{array}{c}\text { Salinity } \\
\text { treatment } \\
\text { level }\end{array}$ & $\begin{array}{c}\text { Sample } \\
\text { number }\end{array}$ & $\begin{array}{c}\text { Plant } \\
\text { height } \\
(\mathbf{c m})\end{array}$ & $\begin{array}{c}\text { Leaf } \\
\text { area } \\
\left(\mathbf{c m}^{2}\right)\end{array}$ & $\begin{array}{c}\text { Leaf } \\
\text { width } \\
(\mathbf{c m})\end{array}$ & $\begin{array}{c}\text { No. of } \\
\text { leaves } \\
\text { per plant }\end{array}$ & $\begin{array}{c}\text { Shoot } \\
\text { weight } \\
(\mathbf{g})\end{array}$ & $\begin{array}{c}\text { Shoot } \\
\text { length } \\
(\mathbf{c m})\end{array}$ & $\begin{array}{c}\text { Root } \\
\text { weight } \\
(\mathbf{g})\end{array}$ & $\begin{array}{c}\text { Root } \\
\text { length } \\
(\mathbf{c m})\end{array}$ \\
\hline $0 \mathrm{mM}$ & Control 1 & 48 & 45 & 2 & 19 & 1.64 & 11.2 & 0.56 & 15.6 \\
$0 \mathrm{mM}$ & Control 2 & 47 & 33.6 & 1.4 & 18 & 1.74 & 14.5 & 0.71 & 19.5 \\
$0 \mathrm{mM}$ & Control 3 & 38 & 26.1 & 1.2 & 18 & 1.27 & 13.6 & 0.59 & 18 \\
$200 \mathrm{mM}$ & Experiment 1 & 38 & 26.55 & 1.2 & 16 & 0.74 & 9.4 & 0.29 & 6.7 \\
$200 \mathrm{mM}$ & Experiment 2 & 48 & 69.2 & 2.2 & 16 & 0.47 & 7.5 & 0.37 & 8.9 \\
$200 \mathrm{mM}$ & Experiment 3 & 43 & 24.75 & 1.1 & 17 & 0.88 & 10.4 & 0.18 & 4.5 \\
\hline
\end{tabular}




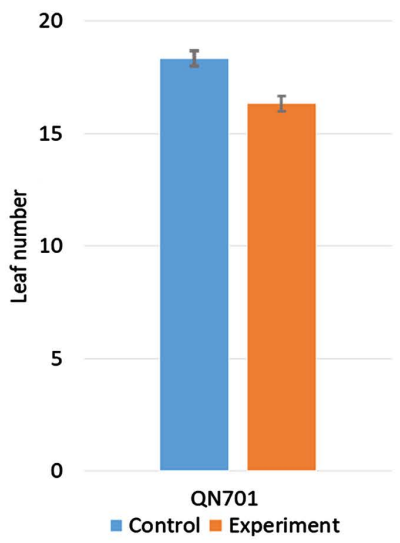

(a)

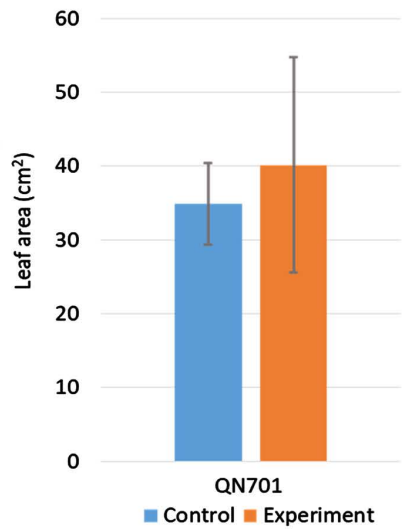

(b)

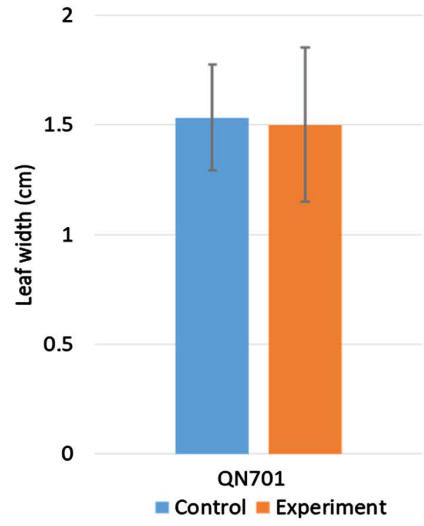

(c)

Figure 1. The effects of salt stress on (a) Number of leaves per plant, (b) Leaf area and (c) Leaf width for both the control and experiment. All error bars represent the standard errors (SEM) of the means of three independent seedling treatments $(n=3)$.

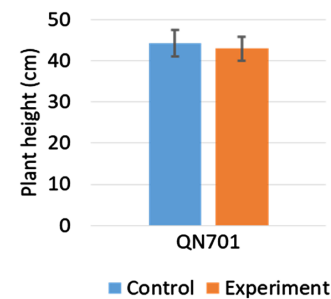

(a)

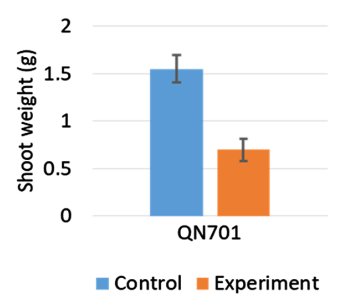

(d)

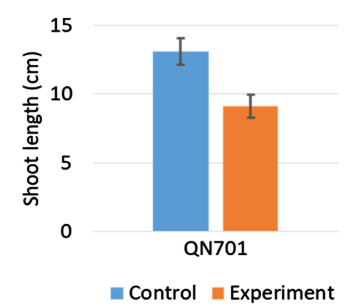

(b)

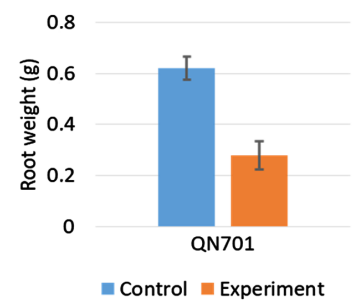

(e)

Figure 2. The effects of salt stress on (a) Plant height; (b) Shoot length; (c) Root length; (d) Shoot; and (e) Root weight. All growth parameters were determined and quantified 16 days after treatment with salt, where the error bars represent the standard errors (SEM) of the means of three independent seedling treatments $(n=3)$.

\subsection{Physiological Responses of Zea mays to Salinity Stress}

\subsubsection{Evaluation of Stomatal Number and Stomatal Density}

For quantification and density of stomata, nail polish imprint method was used as described in Section 2.4.1. The data for the number of stomata on abaxial and adaxial sides of the leaves from all the plant groups (control and treated plants) are displayed in Table 2. In the leaves of both plants (control and experiment) the adaxial (lower) surface had a higher number of stomata as compared to the abaxial (upper) surface (Figure 3(a)). In addition, the leaves of treated (experimental) plants had less stomatal number and density as compared to the leaves of non-treated plants (control) (Figure 3). 
Table 2. Stomatal number and density, from the upper /lower leaf surfaces for the control and experiment.

\begin{tabular}{cccccc}
\hline $\begin{array}{c}\text { Leaf sample } \\
\text { number }\end{array}$ & $\begin{array}{c}\text { Magnification } \\
\text { (ocular } \times \\
\text { objective) }\end{array}$ & $\begin{array}{c}\text { Surface } \\
\text { (upper/lower) }\end{array}$ & $\begin{array}{c}\text { FOV } \\
\text { Control no 1 }\end{array}$ & $\begin{array}{c}\text { Number of } \\
\text { stomata } \\
\text { per FOV }\left(\mathbf{m m}^{2}\right)\end{array}$ & $\begin{array}{c}\text { Stomatal } \\
\text { density }\end{array}$ \\
stomata/mm
\end{tabular}

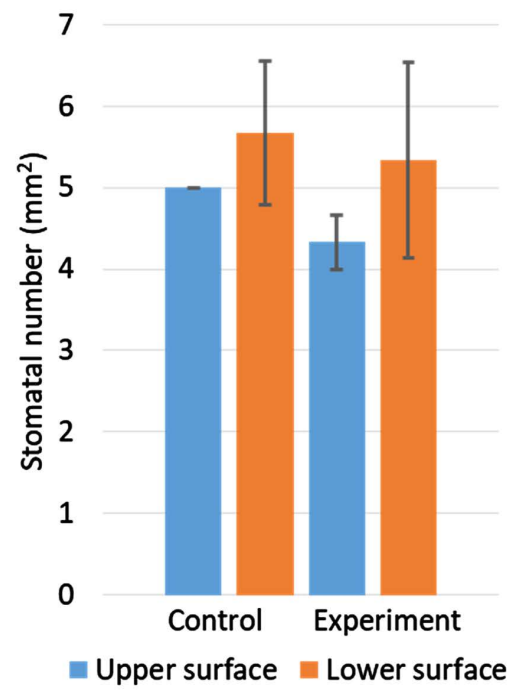

(a)

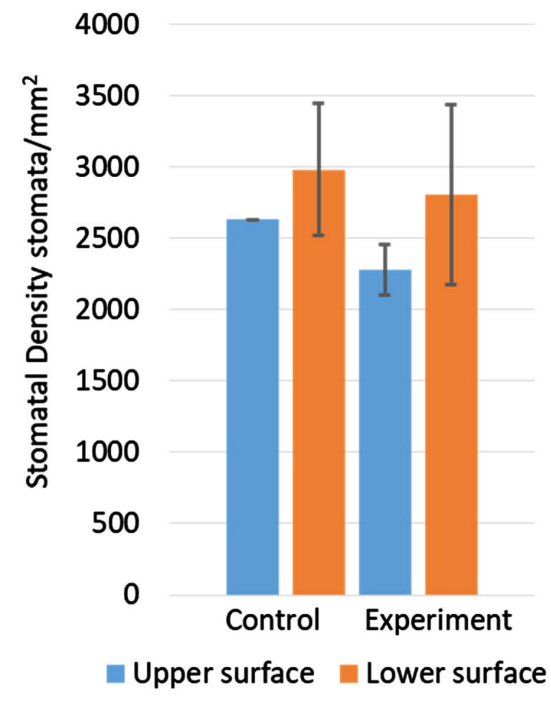

(b)

Figure 3. The effects of salt stress on the (a) Stomatal number and (b) Stomatal density for the upper and lower surfaces of $Z$. mays leaves.

\subsubsection{Photosynthetic Response of Zea mays to Salt Stress}

The physiological effects of salt stress on the photosynthesis rate were assessed in $Z$. mays leaves and a graph was plotted as shown in Figure 4. A decline on the photosynthesis rate was displayed in the experimental leaves as compared to the control, this shows that salt stress inhibited photosynthesis. The photosynthetic responses indicate that treatment of seedlings with salt resulted in a constant state within the first 60 seconds, followed by a slight increase and unstable staggered photosynthesis rate inhibited by salt treatment (Figure 4). 


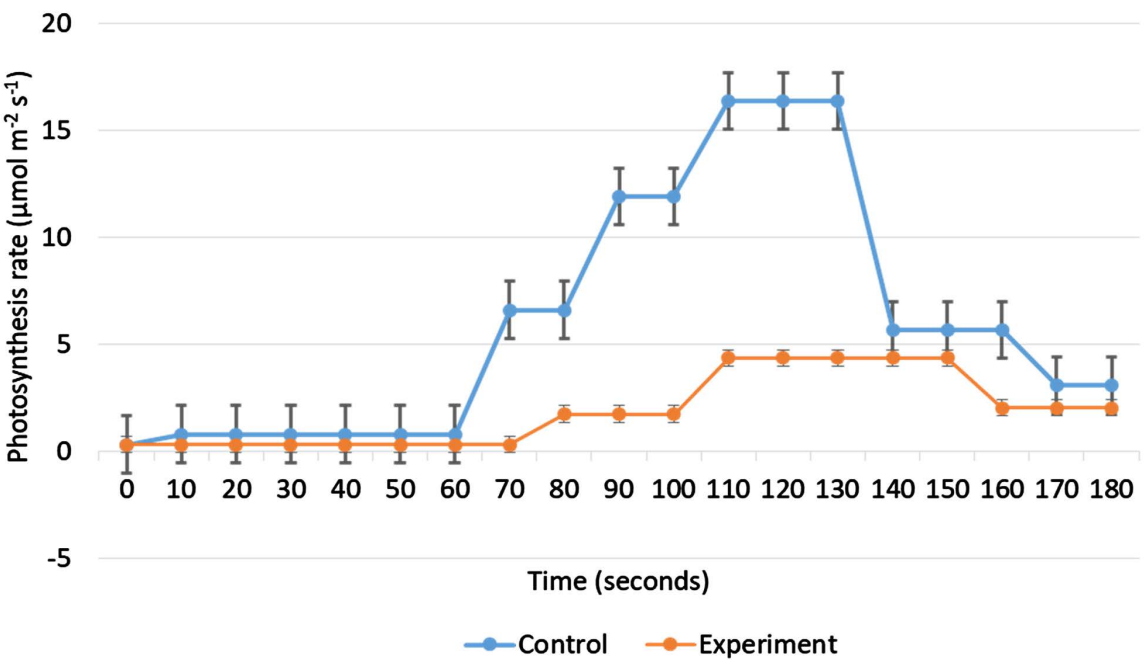

Figure 4. The effect of salt stress on photosynthesis rate of $Z$. mays. The net photosynthesis rates of the control and $200 \mathrm{mM} \mathrm{NaCl}$ treated (experimental) leaves. Error bars represent the standard errors $(\mathrm{SEM})$ of the three biological replicates $(n=3)$ for various response values analyzed by ANOVA.

\subsubsection{Respiration Response of Zea mays to Salt Stress}

The respiration rates for the experiment leaves were strongly reduced. A markedly sharp increase in the 70 seconds was observed on the experiment followed by a decline in the $100^{\text {th }}$ seconds. The overall rates of the respiration for experiment leaves were greater as compared to the control, this shows that salt stress increased respiration rates in $Z$. mays leaves (Figure 5).

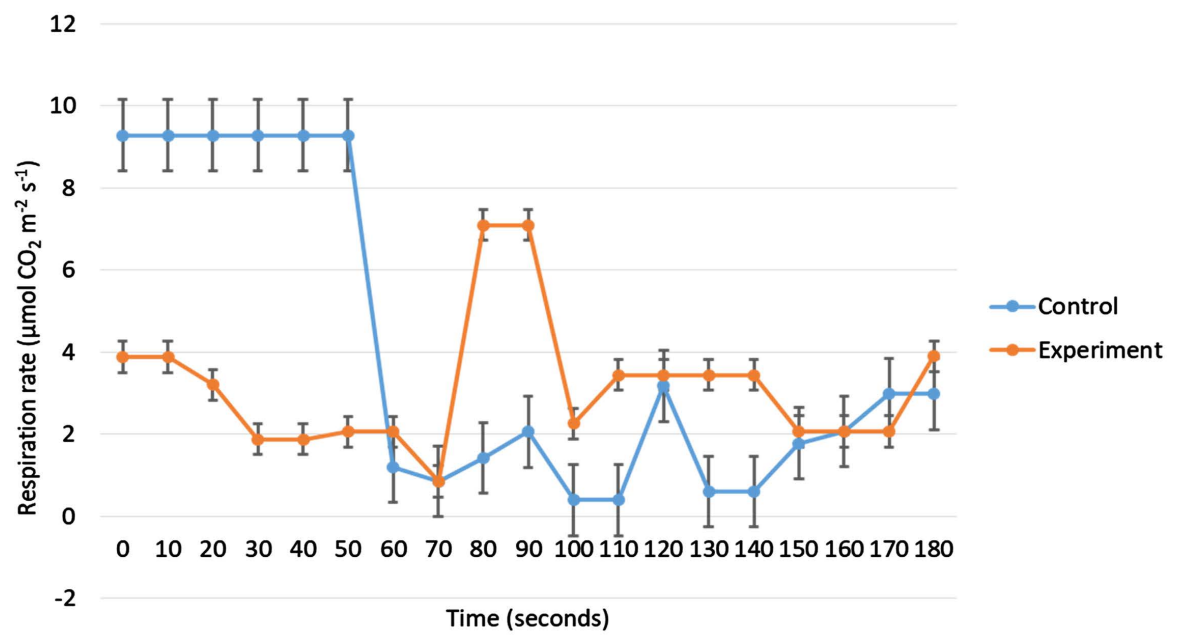

Figure 5. The effect of salt stress on respiration rates of $Z$. mays. The overall rates of respiration for the non-treated (control) and $200 \mathrm{mM} \mathrm{NaCl}$ treated maize leaves (experiment). All error bars represent the standard errors (SEM) of the means of three independent biological replicates $(n=3)$ of different response values obtained and analyzed by ANOVA.

\section{Discussion}

It is well known that salt stress is one of the most deleterious environmental 
stresses that pose a serious threat to food security, since it limits crop growth and productivity especially on cultivated crops [24]. As a result, research on the responses of plants to different environmental stresses is of major interest to the scientific community. In the present study, we focused on the effects of environmental stress on maize, specifically salt stress. Other environmental stresses that crop plants may face include drought or water deficit, heat, low or high temperature and light stress [25]. Salt stress in plants may lead to various morphological, physiological and biochemical alternations which ultimately reduce their growth and productivity [26]. The growth and productivity of crops are adversely affected by salt stress due to ionic imbalances, osmotic stress, changes in physiological and biochemical processes. Thus various approaches are needed to unravel the adaptive mechanisms of salt tolerance, and therefore investigating only the morphological or growth parameters such as plant height, shoot length, root length, plant biomass, etc. would not be adequate to explain the complex interaction demonstrated by plants when faced with salinity stress. Therefore, combined morphological and physiological approaches were used in this study to evaluate salt stress effects in Zea mays. Numerous studies have shown that the growth of different plant species is reduced due to salt stress [15] [27] [28]. Reduction in plant growth is known as a common response to environmental stresses such as salt stress and drought [15] [29].

In our study, QN701 maize cultivar was used to assess the morphological and physiological responses of this cultivar to salt stress. This was conducted by treating 8-day old plants (treated or non-treated) for 16 days under controlled laboratory conditions. Various morphological parameters were affected by salt stress. The number of leaves per plant was reduced, with the control having greater number of leaves as compared to the experimental plants (Figure 1(a)). Similar results were observed by [30] and co-workers in (2001) in tomato under salt stress condition. Surprisingly, our study has shown that the experimental plants had a higher leaf area compared to control (Figure 1(b)), leaf width of both the control and experimental plants was almost the same, so there was no significant difference between the two plant groups (Figure 1(c)), this indicated that salt stress had a positive effect on leaf area and no impact on leaf width of experimental plants. The increase in leaf area of experimental plants may be due to the ability of the plants having a higher leaf tissue tolerance to ion accumulation and osmotic adjustments. These findings were not in agreement with the results observed by [31] on maize where salt stress had a negative effect on leaf area by decreasing leaf area by $15 \%$.

Morphological parameters such as plant height, shoot and root length, shoot and root fresh weight were highly impacted by salinity. According to our results, salt stress reduced plant height although the degree of changes between the control and treated plants were not significant (Figure 2(a)). Reduction in height of various plant species due to increased salinity has been reported to be associated with excess ion accumulation, which results in low yield, limited growth and development [32] [33] [34]. In addition, salt stress reduced shoot and root (length 
and weight) (Figures 2(b)-(e)). Similar results were reported by Zörb et al. [35] on maize, where salt stress decreased root and shoot weight by half. The root and shoot length are considered as important organs for screening salt tolerance in plants because soil particles and solution are in direct contact with these parts. In our study, salt stress negatively affected root and shoot length as manifested by reduced root and shoot length (Figure 2(b) \& Figure 2(c)). Reduction in root and shoot length is often brought about by the increase in osmotic pressure around the roots due to saline environment which ultimately prevent water uptake by roots causing shorter root and shoot length [36]. Leaf stomatal density and stomatal number decreased with salt stress, experimental plants had a less number of stomata and stomatal density on both leaf surfaces (Figure 3(a) \& Figure $3(\mathrm{~b})$ ). Stomatal conductance is highly sensitive to increased salinity stress, hence a decreased conductance illustrates a reduction of water loss in plants as a response mechanism to compensate for the salt accumulation and reduce osmotic pressure [37]. These findings concurred with previous experiments carried out in tomato and quinoa, which indicated a reduction of plant leaf stomatal density under salinity stress [30] [38].

On the basis of the physiological responses, photosynthesis was reduced in experimental plants as compared to the control plants (Figure 4). The major changes occurred within 60 to 140 seconds interval with maximal values of photosynthesis at about $16.38 \mu \mathrm{mol} \cdot \mathrm{m}^{-2} \cdot \mathrm{s}^{-1}$ and $4.38 \mu \mathrm{mol} \cdot \mathrm{m}^{-2} \cdot \mathrm{s}^{-1}$ for control and experimental plants respectively. Reduced photosynthesis rates have also been reported on rice [39] and maize [3] under salt stress condition. Reductions in photosynthesis rates often result due to stomatal closure [40].

Contrary to the strong inhibition of photosynthesis rate, respiration was not inhibited that much as changes in the rates of respiration were much less than those in the rates of photosynthesis. Respiration rate was increased in experimental plants compared to the control plants (Figure 5), the instant increase was observed from the $70^{\text {th }}$ to the $100^{\text {th }}$ seconds with a maximal rate of $7.09 \mu \mathrm{mol}$ $\mathrm{CO}_{2} \mathrm{~m}^{-2} \cdot \mathrm{s}^{-1}$ to $2.26 \mu \mathrm{mol} \mathrm{CO} \mathrm{CO}_{2}^{-2} \cdot \mathrm{s}^{-1}$ respectively. To the best of our knowledge, the effects of salt stress on leaf respiration of maize are not well documented. Nevertheless, our results agreed with some previous studies on the effects of salt stress in other plant species [41] [42].

\section{Conclusion}

Our study evaluated the performance of (QN701) maize cultivar using morphological and physiological growth parameters to induced salinity stress. This cultivar indicated some variation in response to salt stress. Salinity induced several morphological changes in this maize cultivar including the reduction in plant height, leaf numbers, shoot and root length, shoot and root fresh weights. Interestingly of the morphological parameters that were evaluated leaf area showed an increase with salt treatment as opposed to the non-treated plants. Moreover, salinity induced a decrease in various physiological parameters including stomatal number, stomatal density, and photosynthesis, while an increase in the 
rate of respiration was observed. In summary, cultivar response was observed in plant growth development and at a cellular level. The results of this research provided precise knowledge on the morphological and physiological responses of maize to salt stress, and a potential recommendation for maize or related crop breeding screening programs on salinity tolerance.

\section{Conflicts of Interest}

The authors declare no conflicts of interest regarding the publication of this paper.

\section{Contributions by Authors}

TBD and OR conceived the idea and designed the study; provided facilities for the study as well as supervising the experimental work. BM and RRS performed the experiments. All authors contributed to the writing, and approval of the manuscript final version.

\section{References}

[1] Mansour, M.M.F., Salama, K.H.A., Ali, F.Z.M. and Abou Hadid, A.F. (2005) Cell and Plant Response to $\mathrm{NaCl}$ in Zea mays L. Cultivars Differing in Salt Tolerance. General and Applied Plant Physiology, 31, 29-41.

[2] Shah, T.R., Prasad, K. and Kumar, P. (2016) Maize-A Potential Source of Human Nutrition and Health: A Review. Cogent Food and Agriculture, 2, 1166995. https://doi.org/10.1080/23311932.2016.1166995

[3] Henry, C.W., Bledsoe, S.A., Griffiths C., Kollman A., Paul, M., Sakr, S. and Larigrimini, L.M. (2015) Differential Role for Trehalose Metabolism in Salt-Stressed Maize. Plant Physiology, 169, 1072-1089. https://doi.org/10.1104/pp.15.00729

[4] El-Katony, T.M., El-Bastawisy, Z.M. and El-Ghareeb, S.S. (2019) Timing of Salicylic Acid Application Affects the Response of Maize (Zea mays L.) Hybrids to Salinity Stress. Heliyon, 5, E01547. https://doi.org/10.1016/j.heliyon.2019.e01547

[5] Goldblatt, A. (2010) Agriculture: Facts and Trends, South Africa. In World Wildlife Forum.

http://www.foresightfordevelopment.org/sobipro/54/908-agriculture-facts-and-trends -south-africa

[6] Greenway, H. and Munns, R. (1980) Mechanisms of Salt Tolerance in NonHalophytes. Annual Review of Plant Physiology, 31, 149-190.

https://doi.org/10.1146/annurev.pp.31.060180.001053

[7] Sudhir, P. and Murthy, S.D.S. (2004) Effects of Salt Stress on Basic Processes of Photosynthesis: A Review. Photosynthetica, 42, 481-486. https://doi.org/10.1007/S11099-005-0001-6

[8] Umego, C., Ntui, V.O., Ita, E.E., Opara, C. and Uyoh, E.A. (2020) Screening of Rice Accessions for Tolerance to Drought and Salt Stress Using Morphological and Physiological Parameters. American Journal of Plant Sciences, 11, 2080-2102. https://doi.org/10.4236/ajps.2020.1112147

[9] Karimi, G., Ghorbanli, M., Heidari, H., Khavarinejad. R.A. and Assareh, .M.H. (2005) The Effects of $\mathrm{NaCl}$ on Growth, Water relations, Osmolytes and Ion Content in Kochia prostrata. Biologia Plantarum, 49, 301-304. https://doi.org/10.1007/s10535-005-1304-y 
[10] Rasool, S., Hameed, A., Azooz, M.M., Rehman, M, Siddiqi, T.O. and Ahmad, P. (2013) Salt Stress: Causes, Types and Responses of Plants. In: Ahmad, P., Azooz, M. and Prasad, M., Eds., Ecophysiology and Responses of Plants under Salt Stress, Springer, New York, 1-24. https://doi.org/10.1007/978-1-4614-4747-4_1

[11] Munns, R. and Tester, M. (2008) Mechanisms of Salinity Tolerance. Annual Review of Plant Biology, 59, 651-681.

https://doi.org/10.1146/annurev.arplant.59.032607.092911

[12] Wang, W., Vinocur, B. and Altman, A. (2003) Plant Responses to Drought, Salinity and Extreme Temperatures: Towards Genetic Engineering for Stress Tolerance. Planta, 218, 1-14. https://doi.org/10.1007/s00425-003-1105-5

[13] Meloni, D.A., Oliva, M.A., Ruiz, H.A. and Martinez, C.A. (2001) Contribution of Proline and Inorganic Solutes to Osmotic Adjustment in Cotton under Salt Stress. Journal of Plant Nutrition, 24, 599-612. https://doi.org/10.1081/PLN-100104983

[14] Tezara, W., Mitchell, V.J., Driscoll, S.D. and Lawlor, D.W. (1999) Water Stress Inhibits Plant Photosynthesis by Decreasing Coupling Factor and ATP. Nature, 401, 914-917. https://doi.org/10.1038/44842

[15] Nxele, X., Klein, A. and Ndimba, B.K. (2017) Drought and Salinity Stress Alters ROS Accumulation, Water Retention, and Osmolyte Content in Sorghum Plants. South African Journal of Botany, 108, 261-266. https://doi.org/10.1016/j.sajb.2016.11.003

[16] Soussi, M., Ocana, A. and Lluch, C. (1998) Effects of Salt Stress on Growth, Photosynthesis and Nitrogen Fixation in Chick-Pea (Cicer arietinum L.). Journal of Experimental Botany, 49, 1329-1337. https://doi.org/10.1093/jxb/49.325.1329

[17] Moud, A.K. and Maghsoudi, K. (2008) Salt Stress Effects on Respiration and Growth of Germinated Seeds of Different Wheat (Triticum aestivum L.) Cultivars. World Journal of Agricultural Research, 4, 351-358.

[18] Khosravinejad, F., Heydari, R. and Farboodnia, T. (2008) Effects of Salinity on Photosynthetic Pigments, Respiration and Water Content in Two Barley Varieties. Pakistan Journal of Biological Sciences, 11, 2438-2442. https://doi.org/10.3923/pjbs.2008.2438.2442

[19] Kaymakanova, M. (2009) Effect of Salinity on Germination and Seed Physiology in Bean (Phaseolus vulgaris L.). Biotechnology \& Biotechnological Equipment, 23, 326-329. https://doi.org/10.1080/13102818.2009.10818430

[20] Aras, S., Esitken, A. and Karakurt, Y. (2019) Morphological and Physiological Responses and Some WRKY Genes Expression in Cherry Rootstocks under Salt Stress. Spanish Journal of Agricultural Research, 17, e0806. https://doi.org/10.5424/sjar/2019174-15400

[21] Niu, G.H., Xu, W.W., Rodriguez, D.S. and Sun, Y.P. (2012) Growth and Physiological Responses of Maize and Sorghum Genotypes to Salt Stress. International Scholarly Research Notices, 2012, Article ID: 145072. https://doi.org/10.5402/2012/145072

[22] Elings, A. (2000) Estimation of Leaf Area in Tropical Maize. Journal of Agronomy, 92, 436-444. https://doi.org/10.2134/agronj2000.923436x

[23] Voleníková, M. and Tichá, I. (2001) Insertion Profiles in Stomatal Density and Sizes in Nicotiana tabacum L. Plantlets. Biologia Plantarum, 44, 161-165. https://doi.org/10.1023/A:1017982619635

[24] Hasanuzzaman, M. and Fujita M. (2013) Exogenous Sodium Nitroprusside Alleviates Arsenic-induced Oxidative Stress in Wheat (Triticum aestivum L.) Seedlings by Enhancing Antioxidant Defense and Glyoxalase System. Ecotoxicology, 22, 584-596. https://doi.org/10.1007/s10646-013-1050-4 
[25] Fahad, S., Bajwa, A.A., Nazir, U., Anjum, S.A., Farooq, A., Zohaib, A., Sadia, S., Nasim, W., Adkins, S., Saud, S., Ihsan, M.Z., Alharby, H., Wu, C., Wang, D. and Huang, J. (2017) Crop Production under Drought and Heat stress: Plant Responses and Management Options. Frontiers in Plant Science, 29, 8. https://doi.org/10.3389/fpls.2017.01147

[26] Nawaz, K., Hussain, K., Majeed, A., Khan, F., Afghan, S. and Ali, K. (2010) Fatality of Salt Stress to Plants: Morphological, Physiological and Biochemical Aspects. African Journal of Biotechnology, 9, 5475-5480.

[27] Hakim, M.A., Juraimi, A.S., Begum, M., Hanafi, M.M., Ismail, M.R. and Selamat, A. (2010) Effect of Salt Stress on Germination and Early Seedling Growth of Rice (Oryza sativa L.). African Journal of Biotechnology, 9, 1911-1918. https://doi.org/10.5897/AJB09.1526

[28] El Naim, A.M., Khaliefa, E.H., Ibrahim, K.A., Ismaeil F.M. and Zaied, M.B. (2012) Growth and Yield of Roselle (Hibiscus sabdariffa L.) as Influenced by Plant Population in Arid Tropic of Sudan under Rain-Fed. International Journal of Agriculture and Forestry, 2, 88-91. https://doi.org/10.5923/j.ijaf.20120203.02

[29] Parida, A.K. and Das, A.B. (2005) Salt Tolerance and Salinity Effects on Plants: A Review. Ecotoxicology and Environmental Safety, 60, 324-349.

https://doi.org/10.1016/j.ecoenv.2004.06.010

[30] Romeroaranda, R., Soria, T. and Cuartero, J. (2001) Tomato Plant Water Uptake and Plant-Water Relationships under Saline Growth Conditions. Plant Science Journal, 160, 265-272. https://doi.org/10.1016/S0168-9452(00)00388-5

[31] El Sayed, H. and El Sayed A. (2011) Influence of Salinity Stress on Growth Parameters, Photosynthetic Activity and Cytological Studies of Zea mays, L. Plant using Hydrogel Polymer. Agriculture and Biology Journal of North America, 2, 907-920. https://doi.org/10.5251/abjna.2011.2.6.907.920

[32] Munns, R. (2002) Comparative Physiology of Salt and Water Stress. Plant, Cell \& Environment, 25, 239-250. https://doi.org/10.1046/j.0016-8025.2001.00808.x

[33] Abdel-Ghani, A.H. (2009) Response of Wheat Varieties from Semi-Arid Regions of Jordan to Salt Stress. Journal of Agronomy and Crop Science, 195, 55-65. https://doi.org/10.1111/j.1439-037X.2008.00319.x

[34] Farghaly, F.A., Radi, A.A., Abdel-Wahab, D.A. and Hamada, A.M. (2016) Effect of Salinity and Sodicity Stresses on Physiological Response and Productivity in $\mathrm{He}$ lianthus annuus. Acta Biologica Hungarica, 67, 184-194. https://doi.org/10.1556/018.67.2016.2.6

[35] Zörb, C., Schmitt, S., Neeb, A., Karl, S., Linder, M. and Schubert, S. (2004) The Biochemical Reaction of Maize (Zea mays L.) to Salt Stress is Characterized by a Mitigation of Symptoms and not by a Specific Adaptation. Plant Science Journal, 167, 91-100. https://doi.org/10.1016/j.plantsci.2004.03.004

[36] Aydinşakir, K., Erdal, S. and Pamukçu, M. (2013) The Effects of Different Salt Concentrations on Germination and Seedling Parameters of Silage Corn (Zea mays L.) Varieties. Journal of Agricultural Science, 28, 94-100.

https://doi.org/10.7161/anajas.2013.282.94

[37] Iyengar, E.R.R. and Reddy, M.P. (1996) Photosynthesis in Highly Salt-Tolerant Plants. In: Pessaraki, M., Ed., Handbook of Photosynthesis, Marcel Dekker, New York, 897-909.

[38] Orsini, F., Accorsi, M., Gianquinto, G., Dinelli, G., Antognoni, F., Carrasco, K.B.R., Martinez, E.A., Alnayef, M., Marotti, I., Bosi, S. and Biondi, S. (2011) Beyond the Ionic and Osmotic Response to Salinity in Chenopodium quinoa: Functional Ele- 
ments of Successful Halophytism. Functional Plant Biology, 38, 818-831. https://doi.org/10.1071/FP11088

[39] Sultana, N., Ikeda, T. and Itoh, R. (1999) Effect of $\mathrm{NaCl}$ Salinity on Photosynthesis and Dry Matter Accumulation in Developing Rice Grains. Environmental and EXperimental Botany, 42, 211-220. https://doi.org/10.1016/S0098-8472(99)00035-0

[40] Boyer, J.S. (1970) Leaf Enlargement and Metabolic Rates in Corn, Soybean and Sunflower at Various Leaf Water Potentials. Plant Physiology, 46, 233-235. https://doi.org/10.1104/pp.46.2.233

[41] Nieman, R.H. (1962) Some Effects of Sodium Chloride on Growth, Photosynthesis and Respiration of Twelve Crop Plants. Botanical Gazette, 123, 279-285. https://doi.org/10.1086/336163

[42] Kafi, M. (2009) The Effects of Salinity and Light on Photosynthesis, Respiration and Chlorophyll Fluorescence in Salt-Tolerant and Salt-Sensitive Wheat (Triticum aestivum L.) Cultivars. Journal of Agriculture, Science and Technology, 11, 535-547. 